\title{
Mars Science Laboratory Entry Capsule Aerothermodynamics and Thermal Protection System
}

\author{
Karl T. Edquist (Karl.T.Edquist@nasa.gov, 757-864-4566) \\ Brian R. Hollis (Brian.R.Hollis@nasa.gov, 757-864-5247) \\ NASA Langley Research Center, Hampton, VA 23681
}

Artem A. Dyakonov (a.a.dyakonov@larc.nasa.gov, 757-864-4121) National Institute of Aerospace, Hampton, VA 23666

Bernard Laub (Bernard.Laub@nasa.gov, 650-604-5017)

Michael J. Wright (Michael.J.Wright@nasa.gov, 650-604-4210)

NASA Ames Research Center, Moffett Field, CA 94035

Tomasso P. Rivellini (Tommaso.P.Rivellini@jpl.nasa.gov, 818-354-5919)

Eric M. Slimko (Eric.M.Slimko@jpl.nasa.gov, 818-354-5940)

Jet Propulsion Laboratory, Pasadena, CA 91109

William H. Willcockson (william.h.willcockson@Imco.com, 303-977-5094)

Lockheed Martin Space Systems Company, Littleton, CO 80125

Abstract-The Mars Science Laboratory (MSL) spacecraft is being designed to carry a large rover $(>800 \mathrm{~kg})$ to the surface of Mars using a blunt-body entry capsule as the primary decelerator. The spacecraft is being designed for launch in 2009 and arrival at Mars in 2010. The combination of large mass and diameter with non-zero angle-of-attack for MSL will result in unprecedented convective heating environments caused by turbulence prior to peak heating. Navier-Stokes computations predict a large turbulent heating augmentation for which there are no supporting flight data ${ }^{1}$ and little ground data for validation. Consequently, an extensive experimental program has been established specifically for MSL to understand the level of turbulent augmentation expected in flight. The experimental data support the prediction of turbulent transition and have also uncovered phenomena that cannot be replicated with available computational methods. The result is that the flight aeroheating environments predictions must include larger uncertainties than are typically used ${ }^{2}$ for a Mars entry capsule. Finally, the thermal protection system (TPS) being used for MSL has not been flown at the heat flux, pressure, and shear stress combinations expected in flight, so a test program has been established to obtain conditions relevant to flight. This paper summarizes the aerothermodynamic definition analysis and TPS development, focusing on the challenges that are unique to MSL.

\footnotetext{
1

2 IEEEAC paper \#1423, Version 7, Updated February 28, 2007.
}

TABLE OF CONTENTS

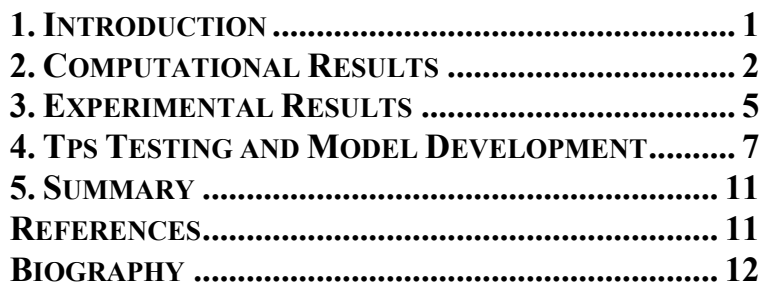

\section{INTRODUCTION}

The Mars Science Laboratory (MSL) will mark a significant advancement in the exploration of Mars through the use of advanced techniques for atmospheric entry and the use of a large rover for surface operations. Guided entry with banking maneuvers will be used to orient the lift vector to minimize range errors and achieve landing accuracy on the order of $10 \mathrm{~km}$ [1]. MSL is currently targeting a hypersonic lift-to-drag ratio (L/D) of 0.24 (trim $\alpha=16 \mathrm{deg}$ ). A main goal of using a guided lifting entry is to achieve parachute deploy conditions (Mach number and dynamic pressure) at a sufficiently high altitude to allow time for the lander to decelerate prior to touchdown.

The MSL rover will require protection from aerothermodynamic loads during hypersonic atmospheric entry. To that end, MSL will use a rigid aeroshell and lightweight ablator thermal protection system (TPS) similar to those used successfully for past missions. Table 1 summarizes key characteristics of successful Mars entry attempts and how they compare to those expected for MSL; the Phoenix lander will be launched in 2007 for arrival in 2008. See [2] for a complete list of Mars entry attempts. 
Table 1. Comparison of Mars Entry Capsules

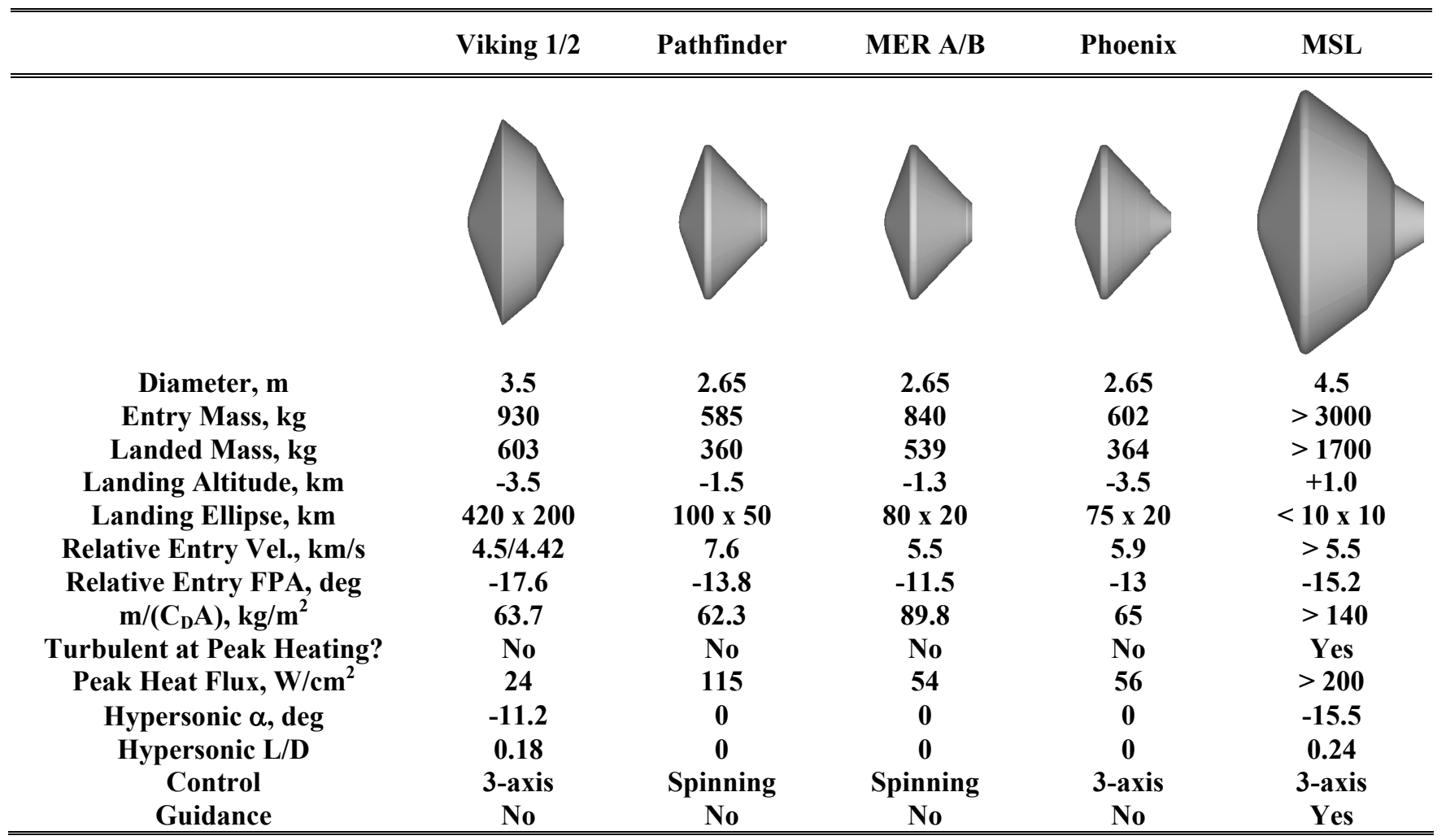

The forebody shape, a 70-degree half-angle spherically blunted cone, was originally chosen for Viking because it gives a low ballistic coefficient $\left(\mathrm{m} / \mathrm{C}_{\mathrm{D}} \mathrm{A}\right)$ and is stable enough to require minimal control system usage [3]. The same forebody shape has been used for all U. S. Mars entry capsules since Viking and will be used as the primary decelerator for MSL. The mass landed by MSL will far exceed the total entry system mass for any of the previous entry systems, and will stretch the limits of the applicability of the Viking style rigid aeroshell entry system [4]. The rover alone is similar in mass to the entire Mars Exploration Rover (MER) entry system. MSL will also land at altitudes much higher than has been attempted before. The added mass and capability to land at higher altitudes requires an aggressive entry profile timeline which, when combined with the large aeroshell and high ballistic coefficient, leads to unprecedented aerothermodynamic loads that will stress the TPS beyond past flight experience. Consequently, computational and experimental methods are being employed extensively for MSL to characterize the aerodynamic heating environments and TPS performance.

\section{Computational Results}

Development of a lightweight TPS capable of handling the predicted environments (heat flux, pressure, shear stress) requires accurate prediction of those environments with proper uncertainties. See [2] for a detailed discussion of the issues related to predicting Mars entry heating. Starting with Mars Pathfinder (MPF), Navier-Stokes flow solvers have been applied with physical models that simulate the nonequilibrium chemical reactions that occur at hypersonic speeds in a high-temperature shock layer [5] - [7]. Laminar convective heating conditions were expected for MPF and the twin Mars Exploration Rovers (MER). In a laminar environment, the heating levels can be determined computationally with uncertainties of about $25 \%$. The MPF predicted peak heat flux $\left(\sim 115 \mathrm{~W} / \mathrm{cm}^{2}\right)$ is the highest experienced to date and was well within the performance limits of the heat-shield ablator (SLA-561V) that will also be used for MSL. See [8] for a description of the MPF heat-shield design.

The same computational methods used for MPF and MER are being employed for characterization of the MSL heating environments [9] - [11]. However, the lifting MSL entry requires the use of full three-dimensional simulations to populate the aerothermal database. In addition, unlike past missions, the prediction of turbulent transition early in the entry trajectory has led to an extensive analysis and testing program for environments definition in addition to TPS response model development and performance assessment.

No accepted method exists for predicting transition to turbulence. In addition, no flight data currently exist for this aeroshell geometry, or any geometry in a Martian environment. However, it is known that transition 
likelihood increases with increasing Reynolds number. Figure 1 shows one method for estimating when boundary layer transition occurs on the MSL heat-shield. The figure shows peak momentum-thickness Reynolds number $\left(\operatorname{Re}_{\theta}\right)$ on the heat-shield as calculated with the LAURA NavierStokes flow solver. The Monte-Carlo based design trajectory associated with Figure 1 gives the maximum integrated heat load (entry velocity $=5.9 \mathrm{~km} / \mathrm{s}$ ). This trajectory requires the thickest heat-shield TPS due to a shallow entry flight path angle leading to a long flight time. A smooth-body transition criterion of $\mathrm{Re}_{\theta}>200$ was established for MSL as a means for computationally predicting the time of transition along the trajectory. A conservative level was chosen due to the fact that other mechanisms (roughness, ablative mass addition, crossflow) may cause transition earlier than would be expected on a smooth aeroshell. For all MSL entry trajectories considered to date, the transition criterion is exceeded well before peak laminar heating. Experimental data (Section 3) support this transition criterion. Thus, the decision was to design the TPS for a completely turbulent heat pulse.

Given that turbulent transition occurs so early in the design

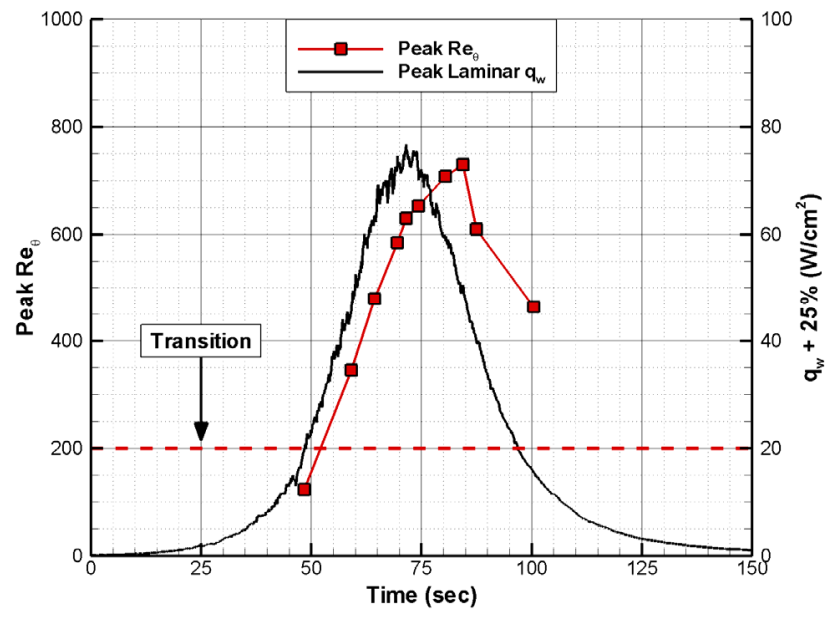

Figure 1. Navier-Stokes Peak Forebody MomentumThickness Reynolds Number and Estimated Peak Laminar Heat Flux

trajectory based on the smooth wall $\mathrm{Re}_{\theta}$ criterion, the choice has been made to design the heat-shield TPS for a fully turbulent heat pulse. This will be the first time a Mars entry capsule has been designed for turbulent conditions at peak heating. Figure 2 shows the impact of turbulence on heating levels along the maximum heat flux trajectory. Navier-Stokes flow field results were obtained for laminar and turbulent conditions at the peak heating point $\left(\mathrm{V}_{\infty}=\right.$ $5330 \mathrm{~m} / \mathrm{s}, \rho_{\infty}=8.37 \times 10^{-4} \mathrm{~kg} / \mathrm{m}^{3}, \mathrm{~T}_{\infty}=163.3 \mathrm{~K}$ ). In these calculations a super-catalytic wall boundary condition was employed, which forces the complete recombination of $\mathrm{CO}_{2}$ and $\mathrm{N}_{2}$ at the wall, thus resulting in the largest possible

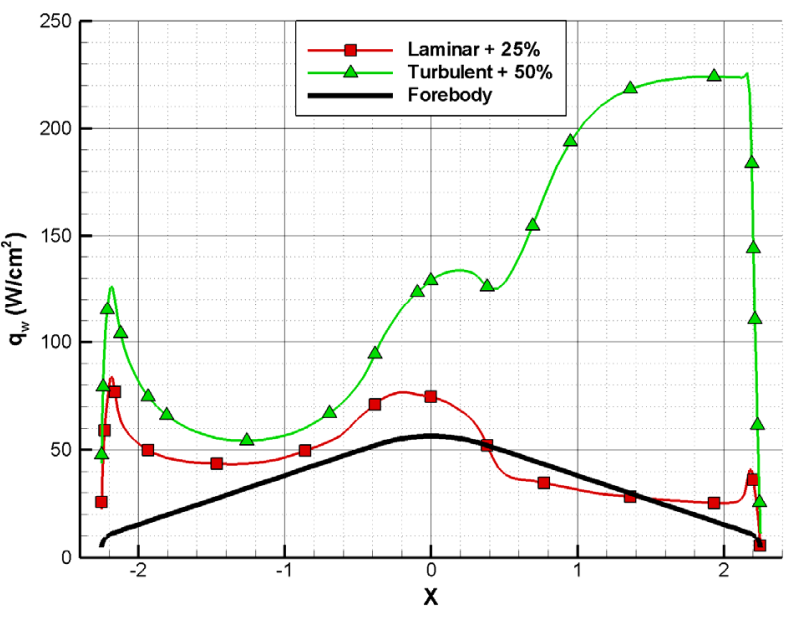

\section{Figure 2. Navier-Stokes Forebody Laminar and Turbulent Heat Flux, Including Uncertainties}

catalytic heat flux. The choice of this boundary condition is consistent with the flight data from the Mars Pathfinder mission [6]. The peak laminar heat flux occurs near the forebody nose and at the shoulder. The turbulent result shows a large augmentation on the leeward $(X>0)$ side of the forebody ( $\alpha \approx 16 \mathrm{deg}$ ). Laminar heating levels for MPF and MER used heat flux uncertainties of about $25 \%$. Given the lack of flight and ground data available for code validation, MSL is carrying a $50 \%$ uncertainty on the predicted turbulent heat flux. The resulting margined heat flux of $225 \mathrm{~W} / \mathrm{cm}^{2}$ is three times the margined laminar heat flux and about double the heat flux experienced by MPF. The turbulent results in Figure 2 represent the highest predicted heat flux within the allowable launch/arrival opportunity space at the time of this paper.

Turbulence also affects the shear stress on the heat-shield. Figure 3 shows the predicted forebody heat flux, pressure, and shear stress with uncertainties applied to the computational results. Whereas MPF experienced the highest heat flux (and virtually no shear stress) at the stagnation point for a ballistic entry, MSL will simultaneously experience high heat flux and shear stress on the leeside heat-shield flank at $\alpha \approx 16 \mathrm{deg}$. The coincidental high heat flux and shear stress levels places extra importance on characterizing TPS performance since the material is subjected to high shear stress at elevated temperatures as the material ablates. The possibility of mechanical removal of ablator material due to high shear makes the TPS design more challenging since such phenomena are inefficient energy accommodators and are not well predicted by current TPS response modeling tools. This situation of high turbulent heat flux and coincidentally high shear stress has necessitated an extensive TPS test program designed to assess material performance for conditions as representative of flight as possible. 


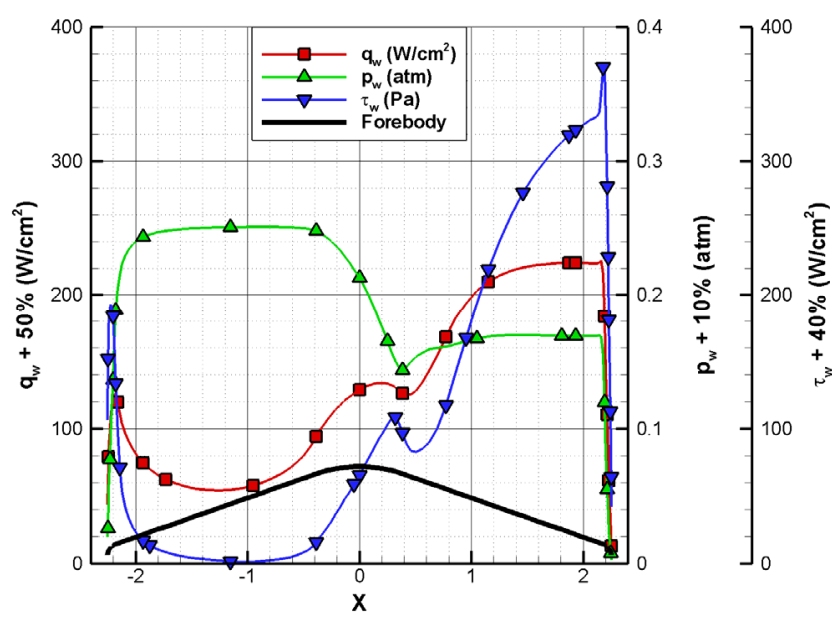

Figure 3. Navier-Stokes Forebody Heat Flux, Pressure, and Shear Stress at Peak Heating Conditions (Including Uncertainties)

Characterization of the afterbody environments is equally challenging for this mission. The prediction of a blunt body wake flow field that is unsteady and possibly turbulent using Navier-Stokes flow solvers requires large computational grids and computer resources (see [11] and [12] for example). Uncertainties for afterbody heating predictions are larger than forebody heating uncertainties due to the difficulty in modeling the wake flow field and sparseness of relevant flight or ground data. Figure 4 shows the MSL afterbody centerline heat flux predictions, including the assumed 200\% uncertainty, at peak dynamic pressure on the maximum heat flux trajectory. The peak dynamic pressure point is shown because it results in the highest afterbody heating rates [11]. A margined heat flux as high as $25 \mathrm{~W} / \mathrm{cm}^{2}$ is predicted at those conditions. For comparison, the MPF margined peak afterbody heat flux

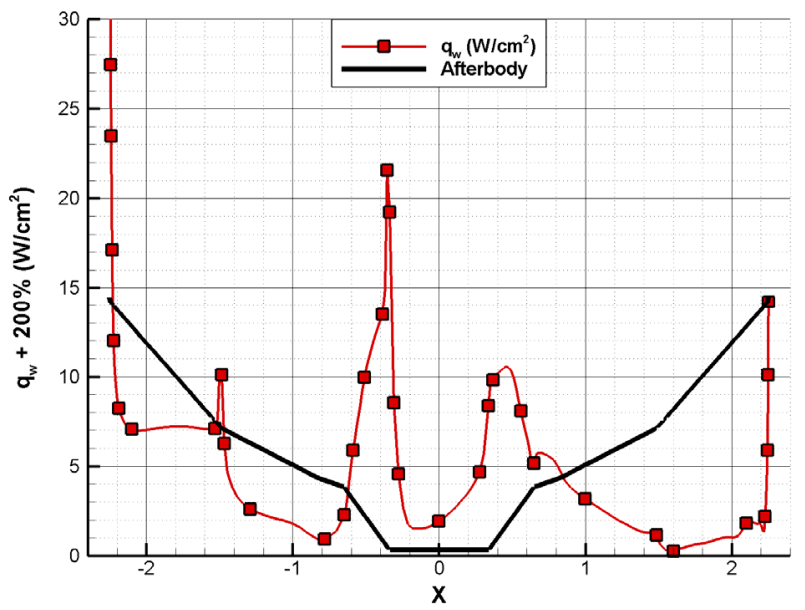

Figure 4. Navier-Stokes Afterbody Heat Flux at Peak Dynamic Pressure Conditions (Including Uncertainties, No RCS Thrusters) was $7-8 \mathrm{~W} / \mathrm{cm}^{2}[5]$.

The afterbody environments for MSL are further complicated by the fact that reaction control system (RCS) jets will be firing throughout the entry trajectory to perform bank maneuvers as part of the guided entry strategy. The RCS thrusters are located on the backshell and their plumes will interfere with the oncoming flow field, causing elevated heating at various locations on the backshell. The uncertainties applied to Navier-Stokes flow field solutions with RCS thruster firings are still to be determined for MSL. A key question for design is how repeated short duration (a few seconds) RCS thruster firings affect TPS performance in the areas where elevated heating occurs. Figure 5 shows an attempt at modeling an RCS thruster firing into the wake flow field using a Navier-Stokes flow solver. A simplified model is used in which the thruster exit plane conditions are imposed on a circular patch of the computational grid. The thruster plume impedes the oncoming supersonic flow and sets up a horseshoe vortex. The vortex impinges on the afterbody surface at various locations and causes locally elevated heat flux. The location and magnitude of augmented heating are a function of the oncoming flow field and are sensitive to the computational grid density. MSL marks the first attempt to model the heating effects of thruster firings for a Mars entry capsule. The magnitude of heating caused by thruster plume interference exceeds the afterbody TPS material limits for MPF and MER. As a consequence, most, if not all, of the afterbody will be covered with the same TPS material used for the forebody.

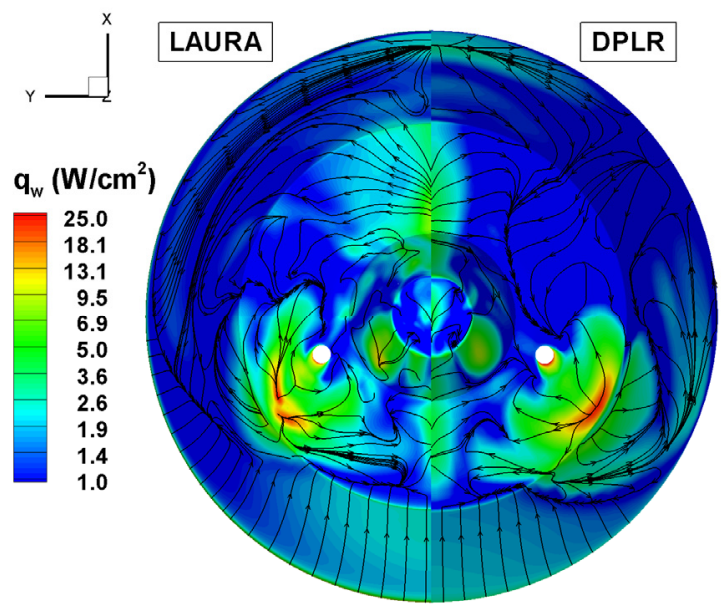

Figure 5. Navier-Stokes Afterbody Heat Flux at Peak Dynamic Pressure Conditions During an RCS Thruster Firing (Not Including Uncertainties) 


\section{EXPERIMENTAL RESULTS}

The large size of MSL, combined with relatively high entry velocity and flight at high angle-of-attack, are expected to produce turbulence well before peak heating, which will lead to much higher convective heating rates than experienced in previous Mars missions. Because little experimental data exist for either turbulent heating of very blunt bodies, or for heating in a high enthalpy $\mathrm{CO}_{2}$ environment, an extensive experimental aeroheating program has been conducted for MSL to obtain data on these phenomena.

Initial testing of the MSL configuration was conducted in the Langley 20-Inch Mach 6 Air Tunnel [13] - [14]. At that time, the heat-shield design incorporated attachment points to the vehicle carrier stage through the forebody. These penetrations were found to cause transition and accompanying high turbulent heating levels at Reynolds numbers much lower than those at which smooth-body

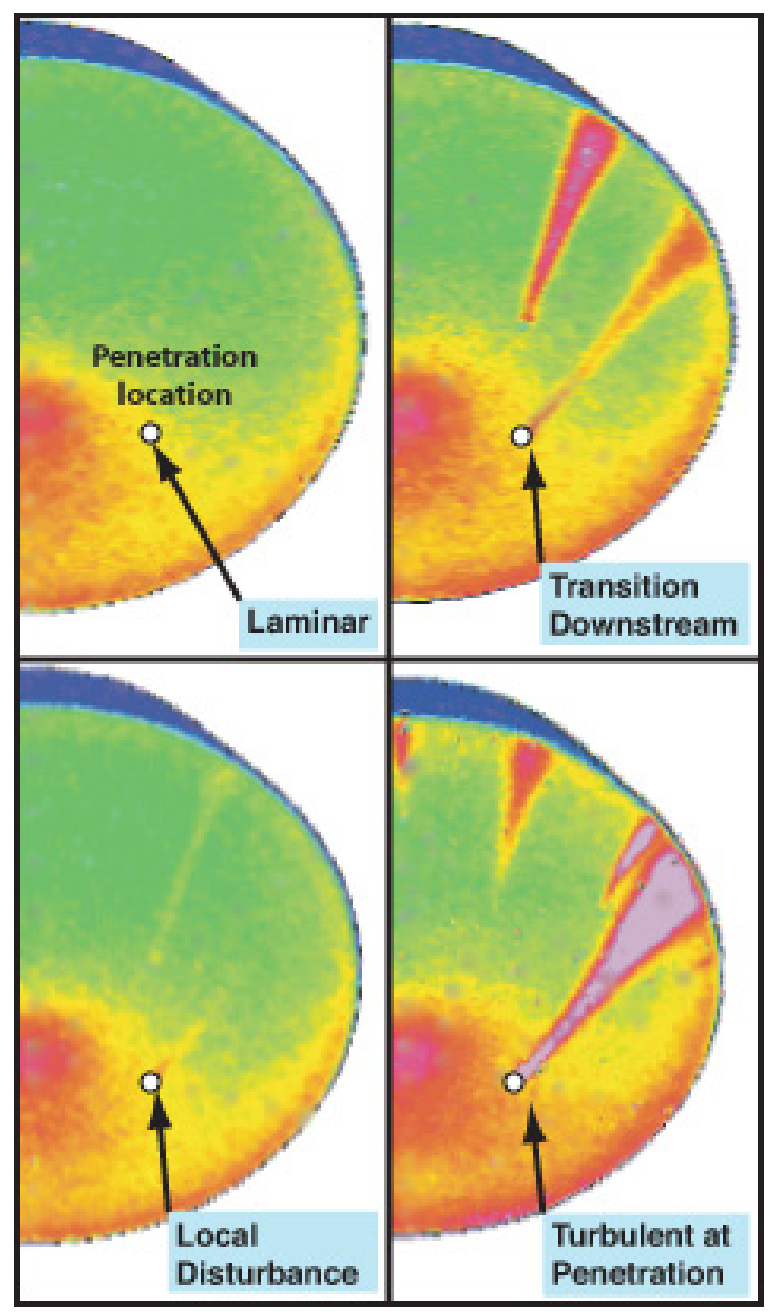

Figure 6. Penetration Effects on Forebody Heating, Langley 20-Inch Mach 6 Air Tunnel transition would occur (Fig. 6). In subsequent designs, the attachment location was moved to the aftbody, thus alleviating the problem of penetration-induced turbulence.

The initial tests indicated that smooth-body transition on the forebody leeside would produce elevated heating rates. A second test was conducted in the Langley 20-Inch Mach 6 Air Tunnel [15] in order to obtain turbulent heating data for comparison to computational results as well as transition onset data. Although $\mathrm{Re}_{\theta}$ or $\mathrm{Re}_{\theta} / \mathrm{M}_{\mathrm{e}}$ are not definitive criteria, transition onset was observed at values much lower than those expected in flight, which reinforces the heatshield design requirement for fully-turbulent flow. Because of model size limitations, no significant running length of fully-developed turbulent flow along the heat-shield could be obtained in this test on the MSL configuration. However, a small running-length of turbulent flow was obtained on a 60 -deg sphere-cone in the same test, and for this case it was found that algebraic turbulence model predictions for heating were approximately $15 \%$ below measured values (Fig. 7).

In order to obtain fully-developed turbulent flow data on the leeside of the MSL configuration, a test was conducted in the Arnold Engineering Development Center (AEDC) Tunnel 9 in $\mathrm{N}_{2}$ at very high Reynolds numbers. Although a full data analysis has not been completed, preliminary comparisons suggest that computational predictions will again be $\sim 15 \%$ lower than the experimental data (Fig. 8).

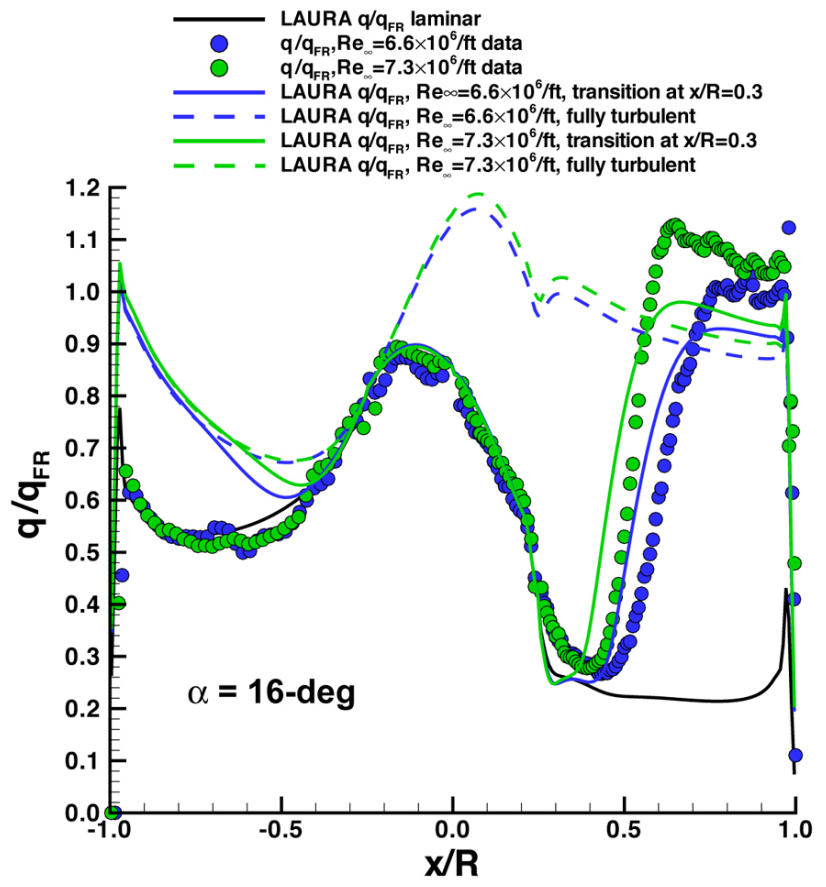

Figure 7. Comparison of Measured and Predicted Turbulent Heating (60-deg sphere-cone), Langley 20Inch Mach 6 Air Tunnel 
In addition to the perfect-gas environments in the Langley and AEDC tunnels, high-enthalpy, reacting, $\mathrm{CO}_{2}$ data (both laminar and turbulent) were obtained in the CUBRC LENSI [15] - [16] and CalTech T5 [17] facilities (Figs. 9-10). Data from these tests were compared to predictions in which both non-catalytic (NC) and super-catalytic (SC) wall boundary conditions were specified. Good comparisons for the laminar cases were obtained with the assumption of a

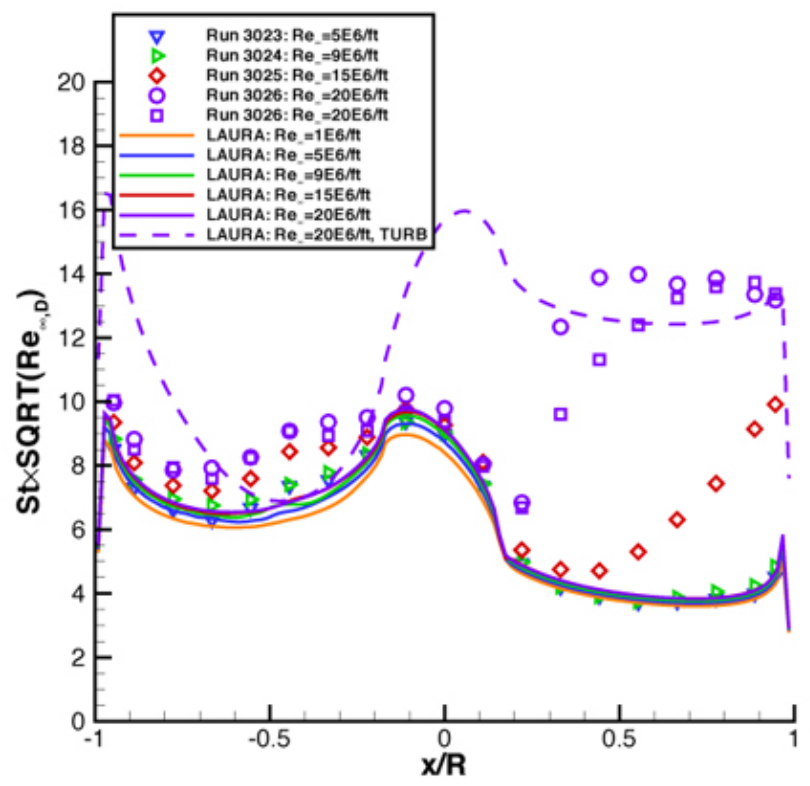

Figure 8. Comparison of Measured and Predicted Laminar/Turbulent Heating, AEDC Tunnel 9

super-catalytic boundary condition; however it is unclear whether the wind tunnel model surface, which was stainless steel in all tests, could catalyze such recombination of $\mathrm{CO}_{2}$. If indeed this did not occur, the data should more closely match the non-catalytic predictions; that they do not indicates that either there was a bias in two separate sets of wind tunnel data, or that the accepted computational models for non-equilibrium $\mathrm{CO}_{2}$ environments are insufficient to reproduce these wind tunnel cases. A further complication was the fact that the turbulent heating data from both facilities were better matched when a non-catalytic wall model was employed (Fig. 11). One possible area in which these models may be lacking is in the description of the vibrational-translation temperature interchange and its effects on dissociation/recombination for the complex triatomic $\mathrm{CO}_{2}$ model [18].

The tests at the Langley Mach 6, AEDC Tunnel 9, and CUBRC LENS-I facilities each showed evidence of heating levels in the windward stagnation region above the predicted laminar heating levels for conditions where the leeside was transitional or turbulent (see for example the region around $x / R=-0.5$ in Fig. 8). $\mathrm{CO}_{2}$ test data from CalTech did not show conclusive evidence of this phenomenon; however, an incipient rise was observed in

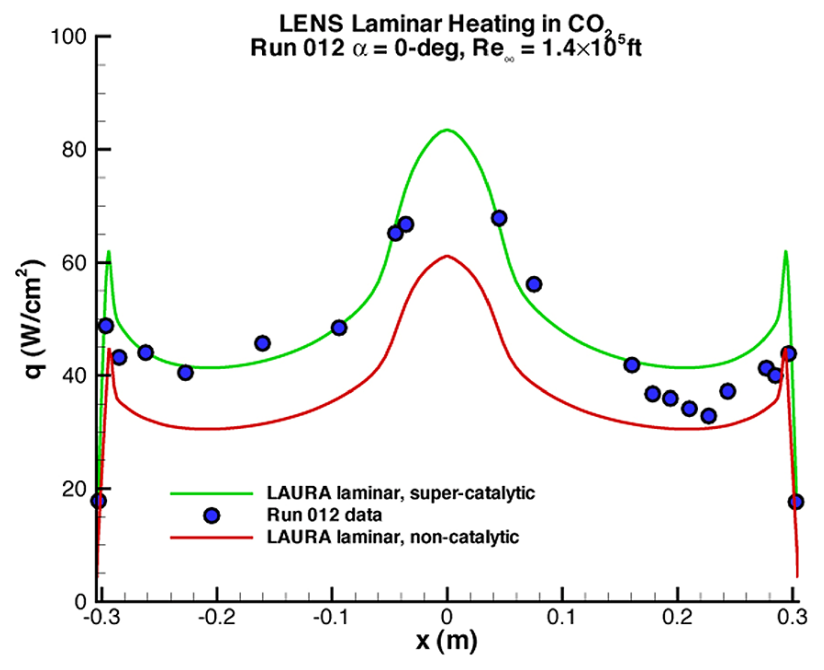

Figure 9: Comparison of LENS Data with Super-
Catalytic and Non-Catalytic Predictions

two of the shots. In addition, this phenomenon was also recorded during testing of the Viking aeroshell [19]. Whether the behavior is due to turbulence, unsteady flow, or some other physical mechanism has not been determined, however its presence in three different wind tunnels confirms that it is not merely an artifact of facility performance. It should be noted that this stagnation region heating augmentation was always less than that observed on the leeside due to turbulence, and thus does not affect the vehicle design margin for the constant thickness heatshield TPS material that is based on the turbulent leeside heating. However, until the root cause of this phenomenon is better understood its effects in a flight (as opposed to ground test) environment remain unquantifiable.

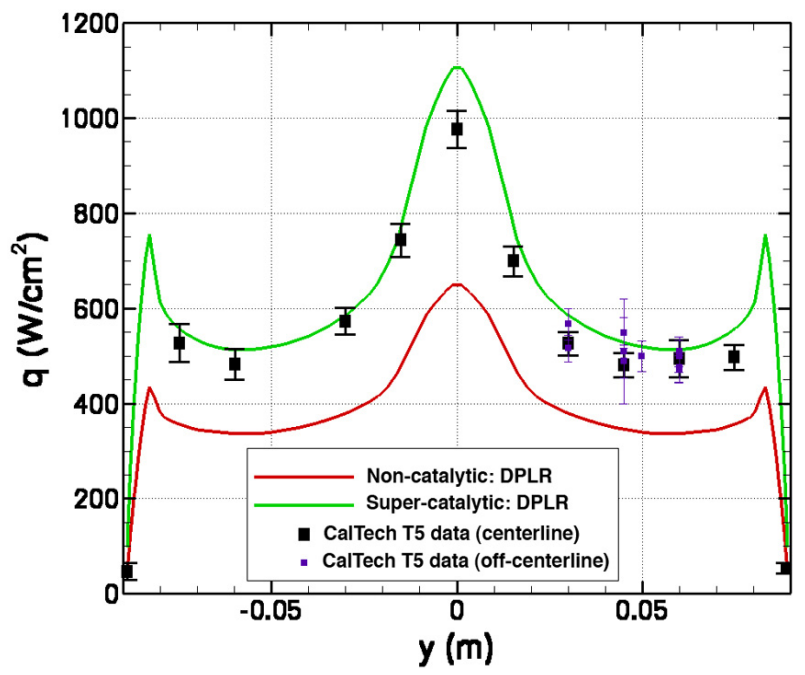

Figure 10: Comparison of T5 Data with SuperCatalytic and Non-Catalytic Predictions 


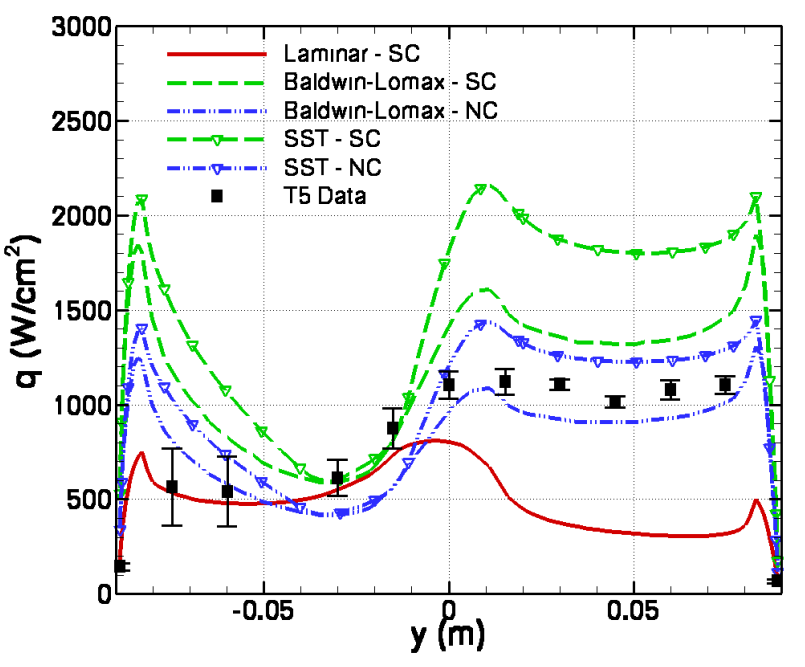

Figure 11. Representative SLA-561V Ablator and Structure Coupon

\section{TPs Testing ANd Model Development}

The material selected for the MSL forebody heat shield is Lockheed Martin's SLA-561V. This material is a lowdensity $\left(\approx 256 \mathrm{~kg} / \mathrm{m}^{3}\right)$ cork-filled silicone in a Flexcore honeycomb. The silicone resin comprises $\approx 25 \%$ (by mass) of the composite, while silica microballoons and chopped fibers constitute $\approx 40 \%$ of the composite. This is the same material used in prior flight heatshields of successful Mars entry missions Mars Viking, Mars Pathfinder (MPF) and Mars Exploration Rover (MER). Originally developed for the 1976 Viking lander missions by the then Martin Marietta Corporation, this lightweight ablator continues to provide mass and cost-efficient heatshield performance for NASA's entry vehicles. In the 1990's, the ablator was recertified for the higher entry heating of the Mars Pathfinder lander as well as being wed to a new lightweight composite structure (Fig. 12). For the MSL mission the aerothermal environment is significantly greater than these previous missions. For example, the peak heat flux on Mars Viking, MER and MPF were $\approx 24,54$, and 115 $\mathrm{W} / \mathrm{cm}^{2}$, respectively. At those conditions SLA-561V acted as a charring insulator but did not experience much, if any, surface recession.

That will not be the case for MSL where it is anticipated that the leeside of the forebody heat shield will experience peak heat fluxes of $\approx 225 \mathrm{~W} / \mathrm{cm}^{2}$, peak pressures between 0.2 and $0.25 \mathrm{~atm}$, and shear stress of almost $400 \mathrm{~Pa}$ (see Fig. 4). At such heat fluxes there is little doubt that SLA-561V will experience surface recession. The windward side will experience pressures in excess of $0.3 \mathrm{~atm}$, but the heat fluxes will be under $100 \mathrm{~W} / \mathrm{cm}^{2}$.

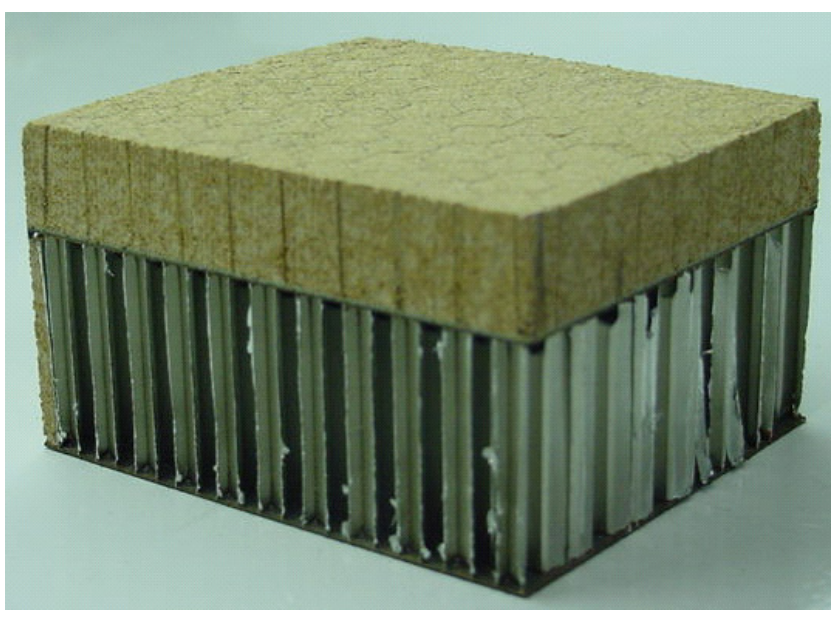

Figure 12. Representative SLA-561V Ablator and Structure Coupon

Prior modeling of the ablator's performance has been successfully represented at NASA and Lockheed Martin by analytic models that used a simplified approach to the basic physics. At Lockheed Martin, the current SLA-561V model is based on simplified physical parameters corroborated by component testing conducted by the Viking program. The complexity of the material makes modeling individual components and the relationship of these individual components difficult. It has simplified models for pyrolysis and char and is based on empirically derived parameters for heat of ablation to account for recession at higher heating. Prior efforts at thermochemical modeling of surface recession showed that the existing analytic model is conservative and has been correlated to test in the range that it has been used for previous Mars missions.

The surface ablation of SLA-561V can involve several mechanisms. Pyrolysis of the silicone resin produces a black carbonaceous char. However, there is no evidence that oxidation of the char is the controlling ablation mechanism. At low pressure and high heat fluxes it appears that surface recession is governed by the melt and vaporization of glass. At higher pressures the limited data suggest that the glass melts but does not vaporize, at least for the limited range of heat fluxes that have been tested recently. In high shear environments the limited data suggest that the melt flows due to aerodynamic shear and might be removed. To develop a reliable TPS design these ablation mechanisms must be understood and modeled on a first principles basis.

It is common practice to develop empirical correlations of ground test ablation data and use such correlations for TPS design. The problem with this approach is that it is almost impossible to simulate actual flight conditions in existing ground test facilities. For example, while it might be possible to simulate flight heat flux and enthalpy, it will not be at flight pressures or shear. Similarly, while it might be 
possible to simulate flight shear and enthalpy, it will not be at flight heat fluxes. Therefore, establishing full traceability from ground to flight is a significant challenge since the ground test data do not represent material performance at actual flight conditions.

A time-proven approach to circumvent the constraints imposed by the limitations of existing ground test facilities is to develop physics- and chemistry-based theoretical models of the relevant material ablation mechanisms since such theoretical models have a basis for extrapolation to actual flight environmental conditions. For some materials where the ablation is governed by the oxidation and sublimation of a carbonaceous char this is straightforward and has been validated for many charring ablators over a broad range of environmental conditions. However, for materials where ablation is governed by the melt, flow and vaporization of glass, the models are more complex.

Because of the expense associated with high energy arcjet testing, a limited set of response data exists for SLA-561V above $100 \mathrm{~W} / \mathrm{cm}^{2}$. Arc jet tests were conducted solely in support of the abovementioned specific missions and generally limited to the limited range of heat fluxes anticipated for those missions. Furthermore, most tests employed bondline thermocouples and not in-depth thermocouples distributed through the thickness. Because the design model for SLA-561V that Lockheed-Martin and Ames have traditionally used for TPS design was not deemed "high fidelity", the MSL project elected to conduct a broad range of arc jet tests to develop a database from which such a high fidelity thermal ablation model could be developed.

At the time this MSL test program was developed (2004) the trajectories under consideration were targeting $\sim 162$ $\mathrm{W} / \mathrm{cm}^{2}$ for the peak forebody heat flux, but mass growth and other launch/arrival opportunities have led to the trajectories under current consideration where peak heat fluxes are as high as $225 \mathrm{~W} / \mathrm{cm}^{2}$. Fortunately, MSL had the foresight to test over a broader range of conditions than were of interest at the time. Lockheed Martin provided $10.16 \mathrm{~cm}$ (4.0-inch) diameter flat-faced samples, $1.90 \mathrm{~cm}$ (0.75-inch) thick, for tests in the NASA Ames Interaction Heating Facility (IHF). All samples contained in-depth thermocouples. Half of the samples had five thermocouples while the remaining half only contained three in-depth thermocouples, as shown in Figure 13. The thermocouples at depths of 0.1 -inch $(2.54 \mathrm{~mm})$ and 0.2 -inch $(5.08 \mathrm{~mm})$ from the surface were Type $\mathrm{R}$ while the other thermocouples were Type K.

Tests were conducted at nominal hot-wall heat fluxes of 30 , $60,90,120,150,180,210,240$ and $300 \mathrm{~W} / \mathrm{cm}^{2}$. At each condition individual samples were exposed for different times to gather data over a range of heat loads. Duplicate tests were conducted at each heat flux/heat load condition

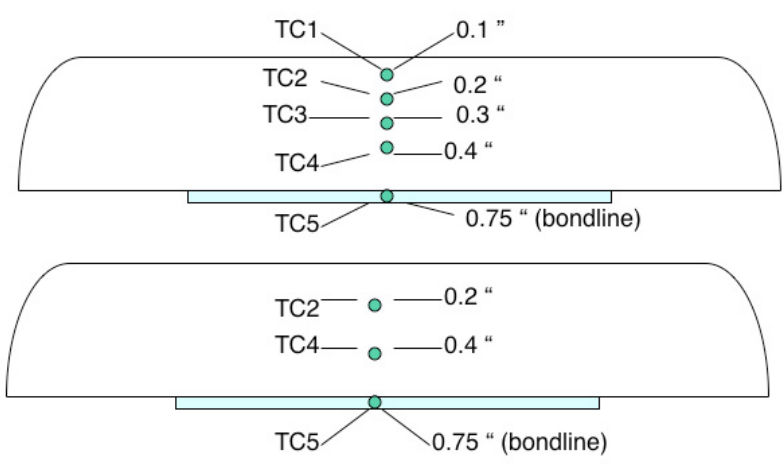

Figure 13. Thermocouple Layout for MSL Arc Jet Test Specimens

wherein one test was with a sample containing five in-depth thermocouples while the second test was on a sample with only three in-depth thermocouples. All tests at heat fluxes above $150 \mathrm{~W} / \mathrm{cm}^{2}$ employed a collar fabricated from SIRCA25, a silicone-infiltrated AIM-22 tile with a density of $\approx 400 \mathrm{~kg} / \mathrm{m}^{3}$. Collars are employed to prevent erosion of the sample edges, which are not aligned with the flow as they would be in a flight heatshield. The large pressure gradient and shear at the shoulder can tear out material from honeycomb cells that are not complete. Collars were not necessary for the tests at lower heat fluxes. Figures 14-17 show representative posttest photos.

Figure 14 shows a black, charred surface with no evidence of glass melt. The central thermocouple plug is evident. Figure 15 shows a surface covered with molten glass but with no evidence of melt flow. The Flexcore honeycomb is clearly evident. Figure 16 shows a sample with a SIRCA 25 collar where melt of the SIRCA collar is apparent. The SLA-561V surface also exhibits molten glass but it appears that the Flexcore is sticking slightly above the SLA in the cells. Figure 17 shows a very similar posttest appearance.

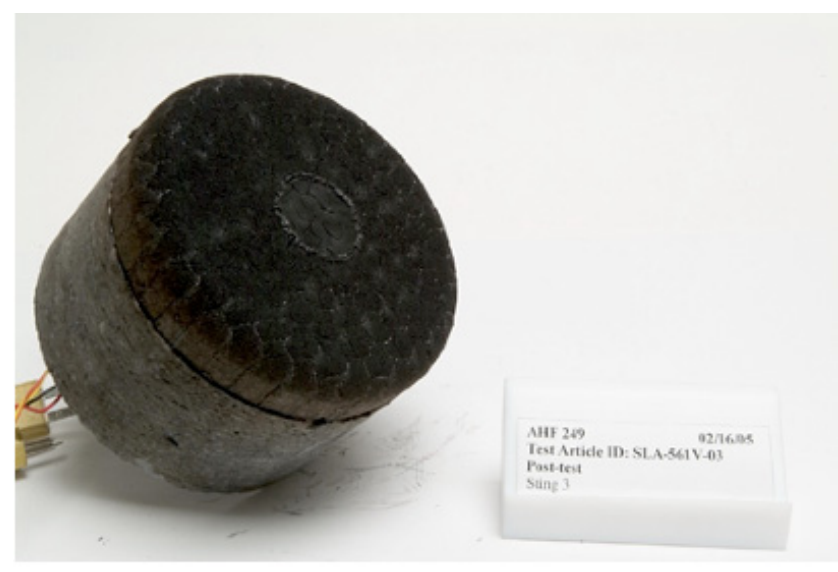

Figure 14. Posttest Photo of SLA-561V Sample Tested at $60 \mathrm{~W} / \mathrm{cm}^{2}$ (Hot-wall) 


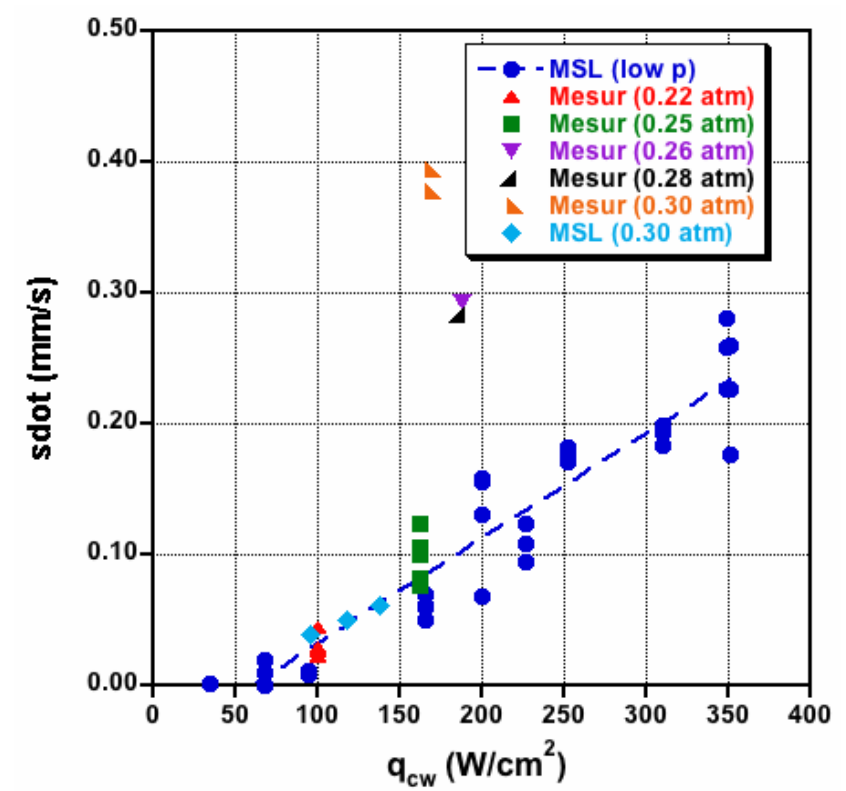

Figure 15. Posttest Photo of SLA-561V Sample Tested at $120 \mathrm{~W} / \mathrm{cm}^{2}$ (Hot-wall)

These photos suggest that at $60 \mathrm{~W} / \mathrm{cm}^{2}$ there is no glass melt or surface recession, just a charred surface. The samples at $90 \mathrm{~W} / \mathrm{cm}^{2}$ looked similar. However, at $120 \mathrm{~W} / \mathrm{cm}^{2}$ there is clear evidence of glass melt with small surface recession. That implies that this condition is near the threshold for surface recession. At higher fluxes there doesn't appear to be much change in surface appearance with the exception that the compound has ablated more than the cell walls themselves. That suggests that the recession of SLA-561V produces a self-induced surface roughness at a relatively small scale $(\sim 1 \mathrm{~cm}$ in planform area) relative to the size of the entry aeroshell.

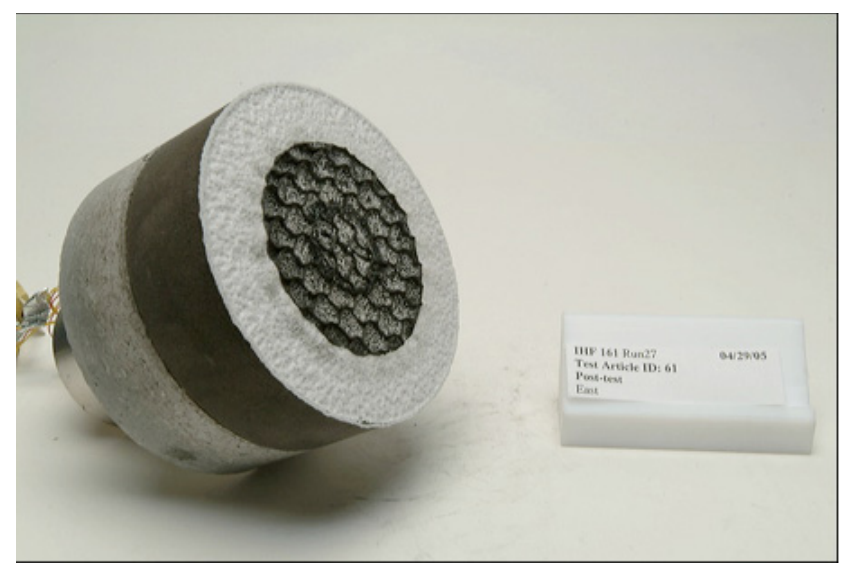

Figure 16. Posttest Photo of SLA-561V Sample Tested at $180 \mathrm{~W} / \mathrm{cm}^{2}$

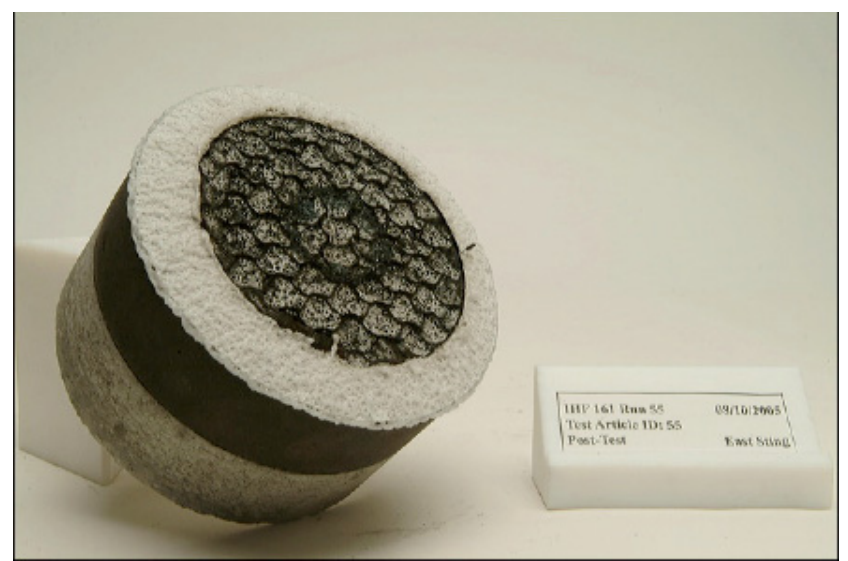

Figure 17. Posttest Photo of SLA-561V Sample Tested at $240 \mathrm{~W} / \mathrm{cm}^{2}$ (Hot-wall)

The recession data acquired in these tests at low to moderate pressures $(\approx 0.085-0.14 \mathrm{~atm})$ correlate well with heat flux, as shown in Figure 18. But these pressures are lower than the peak pressures anticipated during MSL entry through the Mars atmosphere. Consequently, it is important to understand how pressure may influence the performance of SLA-561V. Arc jet screening tests were conducted in 1993-1994 in the Ames IHF facility in support of the MESUR-Pathfinder program [20]. In those tests, SLA$561 \mathrm{~V}$ was exposed to heat fluxes in the range of 100-200 $\mathrm{W} / \mathrm{cm}^{2}$ at pressures from 0.2 to $0.3 \mathrm{~atm}$. It is important to evaluate how the current data compares with these data at higher pressures.

As seen in Figure 18, the recent low-pressure MSL data correlate well with cold-wall heat flux. The MESUR data at pressures at or below $0.25 \mathrm{~atm}$ also correlate well with these data. However, at higher pressures the MESUR data suggest significantly augmented recession rates. But it is important to recognize that at these slightly higher pressures the heat fluxes were also higher. Reference [20] notes that at pressures at and above $0.26 \mathrm{~atm}$ there was evidence of char spallation at the edges of the coupons. Lockheed Martin contends that the MESUR samples were not fabricated to the flight specification since they were very early re-creations of the Viking SLA. While it is hoped that flight-quality SLA-561V will not exhibit the augmented recession rates seen in the MESUR tests at pressures above $0.25 \mathrm{~atm}$, more tests will be required at MSL-relevant heat fluxes and pressures to demonstrate that the MESUR results were an anomaly. 
Under MSL sponsorship a few additional arc jet tests were conducted at a pressure of $\approx 0.3 \mathrm{~atm}$. But these tests were at a cold-wall heat flux between $100-135 \mathrm{~W} / \mathrm{cm}^{2}$. As seen in Figure 18, those data correlate well with the MSL lowpressure results. Clearly it is important to understand the material performance in this range of heat fluxes and pressures since the existing data suggest thermochemical ablation at low pressures and/or moderate heat flux but, possibly, thermomechanical erosion (char spall) may come into play at a combination of higher heat flux and pressure that are representative of anticipated MSL flight environments. Given that char spall is an inefficient ablation mechanism (loss of mass with no energy accommodation) and very difficult to predict reliably, more tests are clearly warranted to fully understand material performance in this regime.

In addition, some regions of the MSL heatshield will experience turbulent flow and relatively high aerodynamic shear. Since SLA-561V has never been exposed to such flight environments it is critical to understand material performance in such environments. However, such flightrepresentative environments are very difficult to simulate in existing ground test facilities. NASA Ames Research Center is planning tests in their Turbulent Duct Facility (TDF) that hasn't been run in several years. While this facility is capable of simulating turbulent flow and shears of interest (but not peak MSL shear), it cannot simultaneously simulate the heat fluxes of interest. It is important to test at heat flux conditions above the recession threshold to evaluate whether aerodynamic shear influences the ablation mechanism, i.e., melt removal rather than melt vaporization. The MSL project is evaluating other facilities to determine if a better simulation is feasible but this may be another case where no existing ground test facility can adequately simulate the conditions of interest.

As discussed earlier, the low-pressure test samples of SLA$561 \mathrm{~V}$ conducted under MSL sponsorship were fully instrumented. Figure 19 and 20 demonstrate the quality of the data acquired.

Currently, an extensive range of laboratory tests is being conducted to collect fundamental data on SLA-561V in support of the development of a physics- and chemistrybased high fidelity thermal/ablation model. Such tests include Thermal Gravimetric Analysis (TGA), Differential Scanning Calorimetry (DSC), elemental composition, heat of combustion, specific heat and thermal conductivity of virgin material. In addition, posttest arc chars will be evaluated to determine the presence of absence of carbon deposition in the char (coking) which can have a significant affect on char density and, consequently, surface recession rate. The thermophysical and thermochemical properties data will be employed with the thermocouple data from the arc jet tests to develop an accurate in-depth thermal response model. This may require that the virgin and char thermal conductivity models account for pressure as well as temperature and density dependence

The biggest challenge will be to develop a more theorybased surface ablation model that can account for changes in ablation mechanisms over different ranges of environmental conditions (e.g., glass melt, glass flow and/or removal due to shear, glass vaporization, char spall). Such a model is critical to the TPS design for a mission that will expose a heritage material to a range of flight aerothermal environments beyond that to which it has been previously flight-qualified. Such theoretical models provide traceability from ground to flight since we cannot simulate the flight environment in existing ground test facilities.

The final sizing of the MSL heatshield will consider this

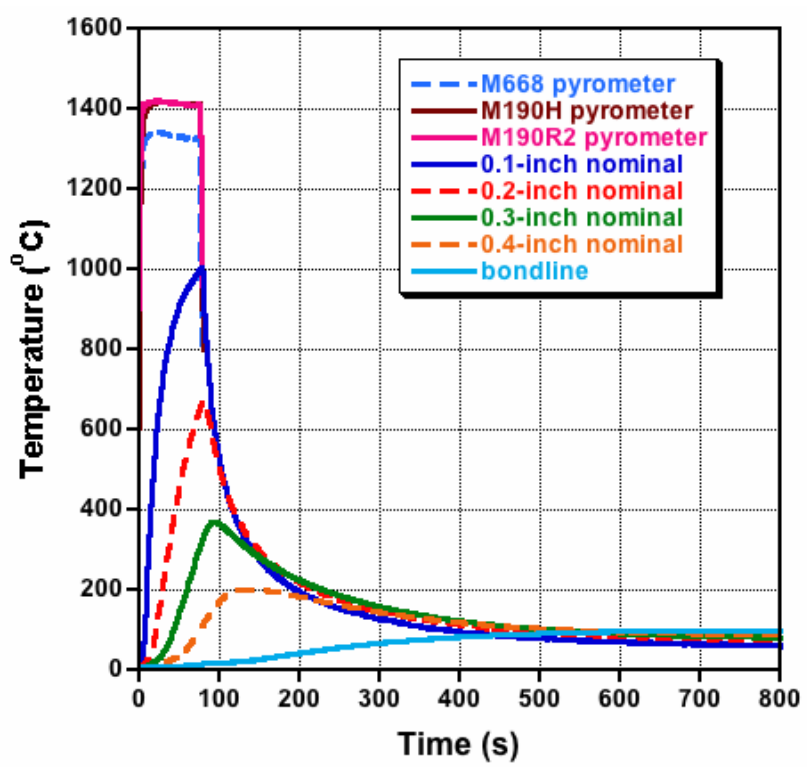

\section{Figure 19. Surface and In-Depth Temperature Data from Test of SLA-561V at $60 \mathrm{~W} / \mathrm{cm}^{2}$ (Hot-wall)}

new undeveloped approach in comparison to the more traditional simplified modeling approaches in order to develop confidence in the results. Certainly the final answer will be subjected to the most rigorous environmental testing possible using flight witness coupons since any analytic model is ultimately subject to unknown shortfalls. 


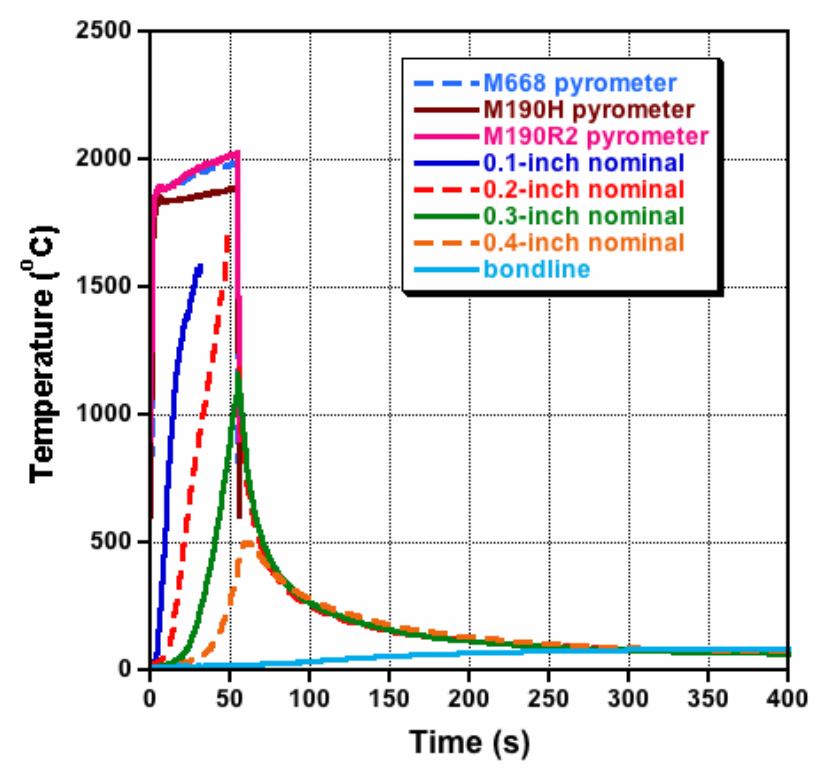

Figure 20. Surface and In-Depth Temperature Data from Test of SLA-561V at $150 \mathrm{~W} / \mathrm{cm}^{2}$ (Hot-wall)

Future work includes more arc jet tests to investigate material performance at flight-representative heat fluxes, pressures and shears. Since the limitations of existing arc jet facilities may frustrate our ability to simulate these conditions simultaneously, we will explore other facilities (e.g., wind tunnels, sleds, etc.) that may be able to simulate critical environmental conditions.

If relevant tests cannot be completed, material performance at these extreme conditions will remain highly uncertain. That will require that the TPS design compensate for those uncertainties with large design margins.

\section{SUMMARY}

Characterization of the Mars Science Laboratory (MSL) entry capsule heating levels is pushing the limits of predictive capabilities and has necessitated extensive testing to validate computational tools and assess thermal protection system (TPS) material performance. Past Mars entry capsules were governed by laminar heating at the heat shield nose, with uncertainties around $25 \%$ placed on Navier-Stokes results. MSL's large ballistic coefficient, large diameter, and non-zero angle-of-attack lead to turbulent heating early in the entry trajectory. Predicted turbulent heating at higher entry velocities approaches 225 $\mathrm{W} / \mathrm{cm}^{2}$ (including an uncertainty of $50 \%$ ), which is three times larger than the margined laminar heat flux and about twice as large as Mars Pathfinder's laminar peak heat flux. The maximum heating location is predicted to coincide with an area of relatively high shear stress, which places additional emphasis on understanding the TPS material response to those conditions. Finally, high angle-of-attack flight and reaction control system (RCS) thruster firings result in afterbody heating levels that exceed past flight experience and will require use of the heat shield TPS material on at least part of the backshell.

An extensive experimental test program has been conducted to observe turbulent heating in ground facilities and provide data to support the computational fluid dynamics (CFD) tools that are used to predict heating on the flight vehicle. Testing in both perfect gas (air and nitrogen) and highenthalpy $\left(\mathrm{CO}_{2}\right)$ facilities have resulted in fully turbulent heating on scale models of the MSL heat shield. Under transitional and fully turbulent conditions, elevated heating occurs on the heat-shield leeside at angle-of-attack. Elevated heating in the stagnation region exceeds laminar CFD predictions for unknown reasons, but the heating is still below maximum leeside turbulent heating.

In general, the computational tools exercised with an algebraic turbulence model underpredict the perfect gas turbulent data by about $15 \%$. Comparisons between highenthalpy data and predictions depend on the surface catalysis boundary condition used in the CFD. Supercatalytic CFD (full recombination of $\mathrm{CO}_{2}$ ) matches laminar heating data well, but it is inconclusive as to whether the stainless steel models can support the necessary recombination reactions.

SLA-561V, a cork-filled silicone in a Flexcore honeycomb, will be used for the heat-shield TPS material. Elevated heating on the afterbody during RCS thruster firings will likely lead to it use on some, if not most, of the backshell. SLA-561V has been successfully used on every previous Mars entry heat-shield. However, the MSL predicted peak heat flux (including a 50\% uncertainty) is roughly twice as high as the most severe flight environments experienced to date during the Mars Pathfinder entry.

Arc jet tests have been conducted at NASA Ames Research Center facilities to understand TPS performance over a wide range of conditions. Stagnation tests at moderate pressures have been conducted for heat fluxes between 30 and 300 $\mathrm{W} / \mathrm{cm}^{2}$, the data from which are being used to develop a high-fidelity ablation response model for SLA-561V. Acceptable recession was observed for all heat fluxes tested. The threshold for surface recession was observed to be near $120 \mathrm{~W} / \mathrm{cm}^{2}$, and differential recession between the ablator and honeycomb cells results in more surface roughness at higher heat fluxes. Additional testing will be completed to better approximate the combination of high heat flux and shear stress, with moderate pressure, expected for MSL during flight. The concern is that high heat flux and shear stress at the same location could lead to recession amounts that are not well understood using existing response models. 


\section{REFERENCES}

[1] Lockwood, M. K., Powell, R. W., Sutton, K., Prabhu, R. K., Graves, C. A., Epp, C. D., and Carman, G. L, "Entry Vehicle Configurations and Performance for the Mars Smart Lander," Journal of Spacecraft and Rockets, Vol. 43, No. 2, March-April, 2006, pp. 258-269.

[2] Wright, M. J., Edquist, K. T., Hollis, B. R., Olejniczak, J., and Venkatapathy, E., "Status of Aerothermal Modeling for Current and Future Mars Exploration Missions", IEEE Aerospace Conference Paper No. 2006-1428, Big Sky, MT, Mar. 2006.

[3] Flaherty, T. "Aerodynamics Data Book, VER-10," TR3709014, Martin Marietta Corporation, Denver Division, June 1972.

[4] Braun, R.D. and Manning, R.M., "Mars Exploration Entry, Descent and Landing Challenges," IEEE Aerospace Conference Paper No. 2006-1076, Big Sky, MT, Mar. 2006.

[5] Chen, Y.-K., Henline, W. D., and Tauber, M. E., "Mars Pathfinder Trajectory Based Heating and Ablation Calculations," Journal of Spacecraft and Rockets, Vol. 32, No. 2, Mar.-Apr. 1995.

[6] Milos, F. S., Chen, Y.-K., Congdon, W. M., and Thornton, J. M., "Mars Pathfinder Entry Temperature Data, Aerothermal Heating, and Heatshield Material Response," Journal of Spacecraft and Rockets, Vol. 36, No. 3, May-June 1999.

[7] Gnoffo, P. A., Weilmuenster, K. J., Braun, R. D., and Cruz, C. I., "Effects of Sonic Line Transition on Aerothermodynamics of the Mars Pathfinder Probe," Journal of Spacecraft and Rockets, Vol. 33, No. 2, March-Apr., 1996, pp. 169-177.

[8] Willcockson, W. H., "Mars Pathfinder Heatshield Design and Flight Experience," Journal of Spacecraft and Rockets, Vol. 36, No. 3, 1999, pp. 374-379.

[9] Edquist, K. T., Liechty, D. S., Hollis, B. R., Alter, S. J., and Loomis, M. P., "Aeroheating Environments for a Mars Smart Lander," Journal of Spacecraft and Rockets, Vol. 43, No. 2, Mar.-Apr., 2006, pp. 330-339.

[10] Edquist, K. T., and Alter, S. J., "Computational Aeroheating Predictions for Mars Lander Configurations," AIAA Paper 2003-3639, June 2003.

[11] Edquist, K.T., "Afterbody Heating Predictions for a Mars Science Laboratory Vehicle," AIAA Paper 20054817, June 2005.
[12] Edquist, K. T., Wright, M. J., and Allen, G. A., "Viking Afterbody Heating Computations and Comparisons to Flight Data,” AIAA Paper No. 2006-0386, Jan. 2006.

[13] Hollis, B. R. and Liechty, D. S., "Transition Due to Heat-Shield Cavities on a Mars Entry Vehicle", Journal of Spacecraft and Rockets, Vol. 43, No. 2, Mar.-Apr., 2006, pp. 354-366.

[14] Liechty, D. S., Hollis, B. R., and Edquist, K. T., "Mars Science Laboratory Experimental Aerothermodynamics with Effects of Cavities and Control Surfaces," Journal of Spacecraft and Rockets, Vol. 43, No. 2, Mar.-Apr., 2006, pp. 340-353.

[15] Hollis, B. R., Liechty, D. S., Wright, M. J., Holden, M. S., Wadhams, T.P., MacLean, M., and Dyakonov, A. "Transition Onset and Turbulent Heating Measurements for the Mars Science Laboratory Entry Vehicle, AIAA Paper 2005-1437, Jan. 2005.

[16] MacLean, M., Wadhams, T. Holden, M. and Hollis, B. R., "Investigation of Blunt Bodies with $\mathrm{CO}_{2}$ Test Gas Including Catalytic Effects," AIAA Paper 2005-4693, June 2005.

[17] Wright, M. J., Olejniczak, J., Brown, J. L, Horning, H. G., and Edquist, K. T., "Computational Modeling of T5 Laminar and Turbulent Data on Blunt Cones, Part 2: Mars Applications," AIAA Paper 2005-0177, Jan. 2005.

[18] MacLean, M. and Holden, M., "Numerical Assessment of Data in Catalytic and Transitional Flows for Martian Entry,” AIAA Paper 2006-2946, Jun. 2006.

[19] Faye-Petersen, R., Sarver, D., and Carroll, H., "Heat Transfer and Pressure Distributions at $\mathrm{M}=8$ on 0.028 Scale Models of the Viking Entry Vehicle," NASA CR 132413, Jul. 1972

[20] Tauber, M., Tran, H., Chen, Y.L., Wercinski, P., Henline, W., and Cartledge, A., "Ames Research Center Arc-Jet Facility Tests of Candidate Heart Shield Materials for MESUR-Pathfinder," NASA Ames Research Center, February 1994.

\section{BIOGRAPHY}

Karl Edquist is an Aerospace Engineer in the Atmospheric Flight and Entry Systems Branch at the NASA Langley Research Center. His areas of expertise are computational aerothermodynamics and aerodynamics. He has authored or co-authored several papers in these fields. He currently is the Aerothermal Lead for the Mars Science Laboratory entry vehicle, responsible for aerothermodynamic 
environments definition. He received his B. S. in Aerospace Engineering from the University of Colorado and M. S. in Aerospace Engineering from the University of Maryland.

Brian Hollis is an Aerospace Engineer in the Aerothermodynamics Branch at the NASA Langley Research Center. His areas of expertise include experimental and computational aerothermodynamics, radiation physics, and boundary-layer transition. He has authored or co-authored over 40 papers in these fields. He received his Ph. D. in Aerospace Engineering in 1997 from North Carolina State University.

Artem Dyakonov is an Aerospace Engineer in the Atmospheric Flight and Entry Systems Branch at the NASA Langley Research Center. His areas of expertise include computational aerothermodynamics/aerodynamics of entry vehicles and engineering aeroheating methods. He has authored or co-authored several papers in his field. He is working on his Ph.D. in Aerospace Engineering at North Carolina State University.

Bernard Laub is a senior member of the staff in the Thermal Protection Materials \& Systems Branch at the NASA Ames Research Center where he is responsible for managing projects involving the use of ablative thermal protection materials. He is an internationally recognized expert in the methodologies for testing, analysis and modeling of ablative thermal protection materials. He received his $B S$ and $M S$ degrees in Aeronautics \& Astronautics from New York University. He has authored or co-authored over 70 papers in the field.

Michael Wright is a Senior Research Scientist at the NASA Ames Research center in the Reacting Flow Environments Branch, specializing in computational aerothermodynamics for Earth and planetary entry vehicles. He is the developer of the DPLR hypersonic CFD code, which is the primary reentry aerothermodynamic analysis tool at Ames. He has authored or co-authored more than 60 papers in the field, and is the two-time recipient of the AIAA Best Thermophysics Paper award (2001 \& 2004). He received his Ph.D. in Aerospace Engineering from the University of Minnesota in 1997.

Tommasso Rivellini received his Bachelors degree in Aerospace Engineering from Syracuse University in 1989 and his Masters degree in Aerospace Engineering from the University of Texas at Austin in 1991. He has been working at NASA's Jet Propulsion Laboratory for the last 15 years developing innovative landing systems for a variety of planetary landers. Tom co-invented the Mars Pathfinder/MER entry, descent and landing system architecture, and was the lead engineer for the airbag subsystem. Tom was the deputy mechanical systems architect for the Mars Exploration Rover mission. He is currently the mechanical systems engineer responsible for the development of the Mars Science Laboratory's entry, descent and landing hardware elements.

Eric Slimko is a Senior Member of the Technical Staff at the Jet Propulsion Laboratory in the Spacecraft Mechanical Engineering Section, specializing in hardware and analyses of entry systems. He has authored and co-authored several papers in the field. He is currently a mechanical system engineer for the Cruise, Entry, Descent, and Landing phase of the Mars Science Laboratory Spacecraft. He received his B. S. in Aerospace Engineering from the University of Michigan and Ph. D. in Computational Neural Systems from the California Institute of Technology.

Bill Willcockson is a senior staff member at Lockheed Martin in Denver, Colorado where he has worked in flight entry systems for the past 20 years. His experience includes flight vehicle development for multiple phases of entry technology, including aerocapture, entry descent \& landing and aerobraking. His flight development and mission operations experience include Magellan, Mars Pathfinder, Mars Global Surveyor, Stardust, Mars Polar Lander, Mars Climate Orbiter, Genesis, Mars Odyssey, Mars 2001 / Phoenix Lander, and Mars Exploration Rover. His education includes B.S., Mathematics and Engineering, Dartmouth College, 1978 and M.S., Aeronautics and Astronautics, Stanford University, 1980. 